\title{
A Revista Engenharia Sanitária e Ambiental no Sistema Brasileiro de Ciência, Tecnologia e Inovação
}

\author{
The Sanitary and Environmental Engineering Journal \\ in the Brazilian Science, Technology and Innovation System
}

\section{Roberto Carlos dos Santos Pacheco', Denilson Sell², Andrea Valeria Steil ${ }^{3}$, Flavio Ceci ${ }^{4}$, Valdir Fernandes ${ }^{5}$, Cleverson Vitorio Andreoli ${ }^{6}$}

\begin{abstract}
RESUMO
Aanálise do histórico de revistas científicaséum dos objetos principais de pesquisas nas áreas de bibliometria, cienciometria, informetria e webometria. Geralmente, essas análises procuram identificar o perfil cronológico dos artigos, autores e contextos editoriais das publicações. Quando entendida como uma organização inserida em um sistema de ciência, tecnologia e inovação (CT\&l), uma revista científica é um agente de memória organizacional, que dissemina e promove conhecimento. Assim, além de análises sobre seu contexto editorial, é relevante verificar outros fatores que posicionam a revista no sistema de CT\&l ao qual se refere. Uma das formas de tratar essa questão se dá pela combinação de métricas da informetria comanálises oriundas da engenharia e da gestão do conhecimento. Neste artigo, aplica-se um modelo multidisciplinar com essa natureza, para verificar a base de conhecimentos criada pela Revista Engenharia Sanitária e Ambiental (Revista ESA) no sistema brasileiro de CT\&l. Foram analisados os 333 artigos publicados entre agosto de 2004 e dezembro de 2012, o perfil curricular dos 816 autores, bem como o perfil de financiamento em CT\&l realizados nos fundos setoriais em temáticas afins à revista, no mesmo período das publicações. Os resultados dessas análises foram verificados por especialistas no domínio das ciências ambientais e engenharia sanitária, com experiência no histórico da revista. Os resultados indicam que o perfil de conhecimentos produzidos pela Revista ESA guarda correspondência com os critérios de financiamento federais para CT\&l, evidenciando o papel que a revista representa como formadora de uma base de conhecimento científico em engenharia sanitária e ambiental.
\end{abstract}

Palavras-chave: cienciometria; engenharia do conhecimento; análise de periódicos; sistema de CT\&l; revista engenharia sanitária e ambiental.

\begin{abstract}
One of the main goals of bibliometrics, scientometrics, informetrics and webometrics is to analyze the history of scientific journals Usually these studies analyze journals history, authors' profiles and how publications have evolved over time. In a broader view a scientific journal can be thought of as a memory agent that promotes and disseminates knowledge in a science, technology and innovation system (STI). This brings other possibilities of understanding the role of scientific journals in STI systems. We address this challenge by combining informetrics with knowledge engineering and management techniques. In this article, we apply a multidisciplinary model to verify the knowledge base created by the Brazilian Scientific Journal called "Engenharia Sanitária e Ambiental" (ESA) in the Brazilian STI system. We analyzed the 333 articles published between August 2004 and December 2012. We also studied the national database of curricula in Brazil to analyze the profiles of the 816 authors and a national database, to check for public funding in subjects published in ESA. We concluded that both the knowledge published in ESA and the areas funded by national grant in Brazil have evolved in a similar way. This indicates that ESA plays a significant role as a memory agent in environmental and sanitary engineering in Brazil.
\end{abstract}

Keywords: scientometrics; knowledge engineering; scientific journal analysis; science, technology ando innovation system; environmental and sanitary engineering journal.

\footnotetext{
'Doutor em Engenharia de Produção pela Universidade Federal de Santa Catarina (UFSC). Professor do Departamento de Engenharia do Conhecimento e do Programa de Pós-graduação em Engenharia e Gestão do Conhecimento da UFSC - Florianópolis (SC), Brasil.

2Doutor em Engenharia de Produção pela UFSC. Professor do Departamento de Administração Pública da Universidade do Estado de Santa Catarina (UDESC) e do Programa de Pós-graduação em Engenharia e Gestão do Conhecimento da UFSC. Diretor do Instituto Stela - Florianópolis (SC), Brasil.

${ }^{3}$ Doutora em Engenharia de Produção pela UFSC. Professora do Departamento de Psicologia e do Programa de Pós-graduação em Engenharia e Gestão do Conhecimento da UFSC - Florianópolis (SC), Brasil.

${ }^{4}$ Doutorando em Engenharia e Gestão do Conhecimento pela UFSC. Professor do Curso de Sistemas de Informação da Universidade do Sul de Santa Catarina (UNISUL) Florianópolis (SC), Brasil.

${ }^{5}$ Doutor em Engenharia Ambiental pela UFSC. Professor Titular do Programa de Pós-graduação em Tecnologia da Universidade Tecnológica Federal do Paraná (UTFPR) Curitiba (PR), Brasil.

${ }^{6}$ Doutor em Meio Ambiente e Desenvolvimento pela Universidade Federal do Paraná (UFPR). Professor do Mestrado em Governança e Sustentabilidade do Instituto Superior de Administração e Economia da Faculdade Getúlio Vargas (FGV) - Curitiba (PR), Brasil.

Endereço para correspondência: Roberto Carlos dos Santos Pacheco - Rua Almirante Barroso, 45/A/302 - João Paulo - 88030-460 - Florianópolis (SC), Brasil -

E-mail: pacheco@egc.ufsc.br

Recebido: O2/O4/14 - Aceito: 26/01/15 - Reg. ABES: 132891
} 


\section{INTRODUÇÃO}

A análise de revistas científicas é tradicionalmente objeto de estudos das áreas da cienciometria (DOBROV \& KARENNOI, 1969; WILSON, 1999) e de disciplinas relacionadas, como a informetria (NACKE, 1979; BROOKES 1988), a bibliometria (OTLET, 1934; PRITCHARD, 1969), a cibermetria (BJÖRNEBORN \& INGWERSEN, 2004) e a webometria (ALMIND \& INGWERSEN, 1997). Com diferentes fontes de informação, essas disciplinas têm buscado respostas para a evolução da atividade científica quanto a conhecimentos produzidos, perfis de autores, contextos institucionais, critérios de avaliação, entre outros fatores que auxiliam na compreensão dos processos de produção cientifica e bibliográfica da revista (BJÖRNEBORN \& INGWERSEN, 2004).

Além de permitir analisar o ciclo de processos, os atores e os fatores associados à publicação científica, métodos informétricos podem contribuir na análise sistêmica de ciência, tecnologia e inovação (CT\&I) enquanto fatores condicionantes ao desenvolvimento tecnológico, social e econômico (HUANG; CHANG; CHEN, 2012). Revistas científicas são, ao mesmo tempo, veículos de comunicação dos resultados advindos dos processos de criação de conhecimento técnico-científico (WITTER \& MARIA, 2005) e registro da propriedade autoral e da memória com que um sistema de atores produtores de conhecimento evolui e, portanto, parte fundante do fazer e do desenvolvimento da ciência (SAMPAIO; SABADINI; LIGUANOTTO, 2002).

Essa inserção estratégica das revistas em sistemas técnico-científicos é mais concretamente observada nos processos de avaliação, tanto de resultados científicos como de processos de formação em ciência. Avaliar produção científica implica em considerar índices qualitativos para os veículos de publicação dessa produção. No Brasil, esse tem sido um dos desafios de órgãos de acreditação e fomento, como a Coordenação de Aperfeiçoamento de Pessoal de Nível Superior (CAPES) que, para tal, criou um sistema de avaliação, denominado Webqualis (CAPES, 2011).

Nesse contexto de análise, uma revista científica pode ser concebida como um ator organizacional de criação e difusão de conhecimentos em um sistema de CT\&I. Em método recém-criado, os autores partem da percepção da revista como uma agente de memória organizacional no sistema de CT\&I ao qual se refere. A partir dessa visão, preocupações da gestão do conhecimento podem ser tratadas com a combinação de indicadores e métricas da informetria com sistemas de análise da engenharia do conhecimento (EC) (PACHECO et al., 2012).

O objetivo, portanto, é contextualizar uma revista científica como um ator organizacional relevante não somente para os atores produtores de conhecimento científico, mas, também, para gestores públicos responsáveis por estabelecer políticas e programas de fomento à CT\&I, organizações empresariais e atores sociais interessados no potencial de valor socioeconômico do conhecimento promovido pela revista. Neste artigo, o método é aplicado à Revista Engenharia Sanitária e Ambiental (Revista ESA), que será, então, percebida como um agente de memória e comunicação técnico-científica no sistema brasileiro de CT\&I, nas dimensões da engenharia sanitária e das ciências ambientais (temáticas-alvo da Revista ESA).

\section{METODOLOGIA}

Na Figura 1 apresenta-se a visão geral da abordagem utilizada nesta pesquisa para analisar o papel de revistas científicas no contexto de um sistema de CT\&I.

A necessidade de uma abordagem multidisciplinar para analisar a revista científica é decorrente de dois fatores:

1. da busca por respostas sobre o papel que um periódico tem para os diferentes atores de um sistema técnico-científico; e

2. da necessidade de se considerar não somente as publicações na revista, mas também fontes de informação geradas pelo sistema de CT\&I em que ela se contextualiza, como currículos de pesquisadores e bases de fomento a projetos.

Com isso, os objetos de estudo e as disciplinas representados na Figura 1 são combinados em um contexto de análise para responder às questões de pesquisa apresentados no Quadro 1.

No modelo descrito anteriormente, a análise de uma revista como um ator de memória organizacional em um sistema técnico-científico inicia pela formação do histórico de suas publicações. No caso da Revista ESA, tomou-se a totalidade dos trabalhos digitalizados no Sistema SciELO, com a análise de 333 artigos publicados no período de agosto de 2004 (vol. 9, n. 3) a dezembro de 2012 (vol. 17, n. 4), o perfil curricular dos 816 autores (via currículos disponíveis na Plataforma Lattes) e o perfil de financiamento em CT\&I realizados nos fundos setoriais do Ministério da Ciência, Tecnologia e Inovação (MCTI), em temáticas afins à revista, no mesmo período das publicações.

Nas seções a seguir, apresentamos os resultados das análises da Revista ESA, sob o contexto do Quadro 1. Inicialmente são apresentados os resultados obtidos a partir de análises baseadas informetria. Na sequência, são abordados os resultados da aplicação de técnicas da engenharia do conhecimento para a estratificação de temáticas abordadas nas revistas e para a análise do aporte financeiro implementado pelos fundos setoriais.

\section{Preparação das bases de dados}

Para preparar os dados da Revista ESA foram efetivados:

1. extração dos arquivos digitais (formato PDF), com todos os artigos publicados no período de interesse;

2. tabulação dos dados sobre cada artigo (data, título, autores, afiliações, palavras-chave e resumo);

3. análise e tabulação de dados constantes nos Currículos Lattes dos autores e de especialistas nas áreas da revista no Portal Inovação; e

4. preparação dos dados de projetos financiados pelos fundos setoriais no período de interesse. Esses procedimentos estão descritos no Quadro 2. 


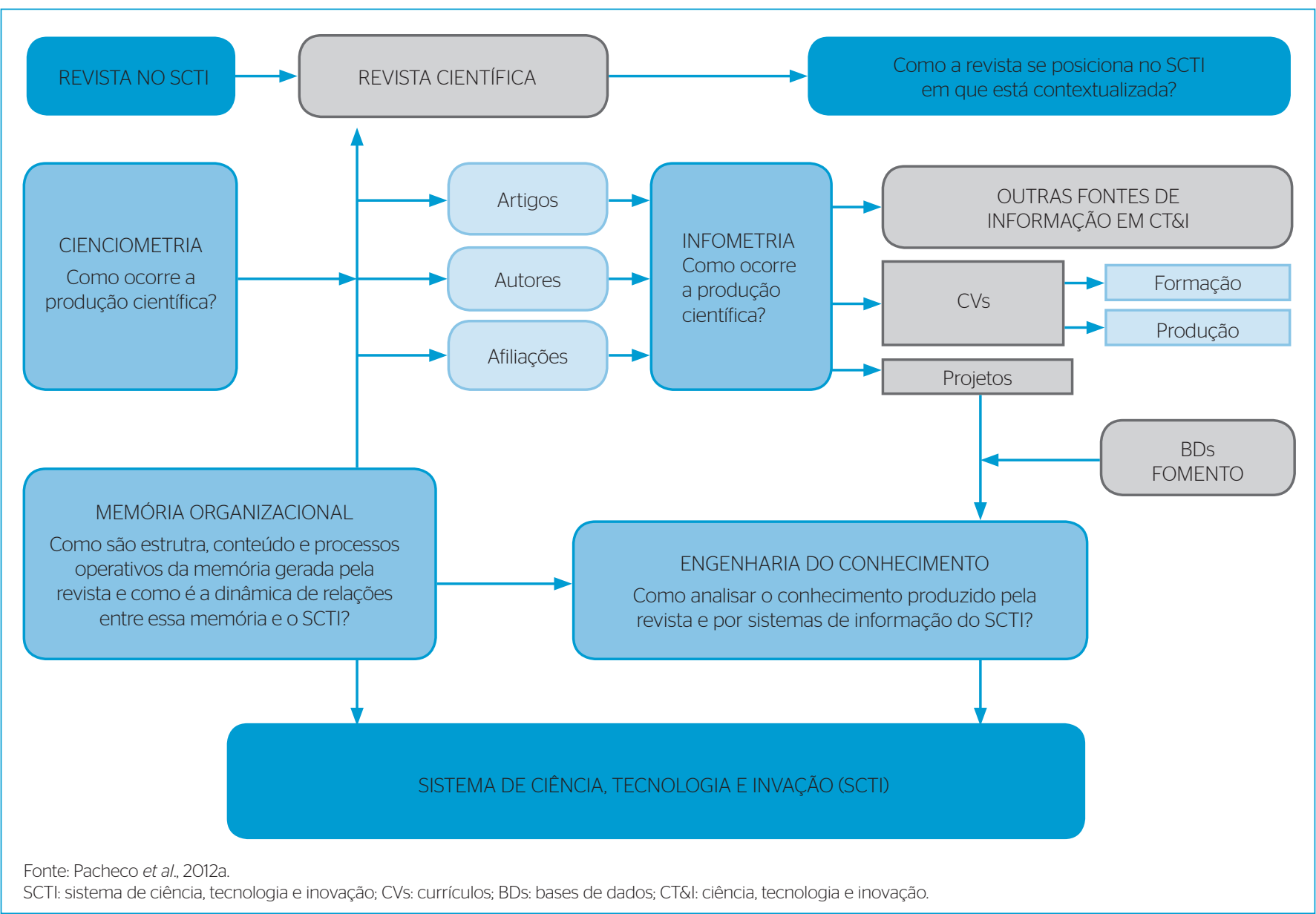

Figura 1 - Visão de mundo da abordagem proposta.

Quadro 1 - Elementos do procedimento metodológico da abordagem proposta.

Contexto da pesquisa: SCTI, seus atores e o papel de uma revista científica como veículo de memória e difusão de CT\&l.

Objeto de investigação: a revista científica como componente do SCTI.

Objetivo: analisar o posicionamento de uma revista científica em seu SCTI, sob as perspectivas de produção de ciência e de relação com os demais processos nesse sistema (ex: planejamento e fomento).

Fontes de informação: repositório de artigos da revista e bases de dados de sistemas de informação do SCTI.

\section{Questões de investigação}

1. Qual é o perfil do conhecimento registrado pela revista científica?

- Qual é seu conteúdo? Que temáticas têm sido priorizadas?

- Quem é e qual é o perfil de seus autores? Como são a formação e a experiência dos mesmos?

- Qual é o capital relacional/social de sua comunidade de autores? A que ICTIs pertencem os autores?

2. Como a revista se posiciona no SCTI?

- Perfil do SCTI: como contextualizar o perfil da revista no SCTI em que ela se situa?

- Planejamento: as temáticas da revista são frequentes em editais ou em programas de CT\&l?

- Fomento: qual é a aderência das temáticas na revista às prioridades de fomento? Os autores na revista têm recebido fomento à sua prática científica?

\section{Procedimentos metodológicos}

Gestão da informação: coleta e análise dos dados da revista e das demais fontes de informação utilizadas.

Análise do conhecimento registrado na revista: natureza, conteúdo e implicações no SCTI.

Análise da memória criada pela revista percebida como veículo de difusão e comunicação do SCTI.

\section{Disciplinas}

Sistemas de CT\&l: para caracterizar os atores de CT\&l, seus perfis e relações no contexto da revista científica.

Cienciometria e informetria: para incluir análises cientométricas e informétricas da revista na proposta.

Memória organizacional: para caracterizar a revista científica como um meio de armazenamento, retenção e difusão em um SCTI.

Engenharia do conhecimento: para adicionar métodos e técnicas aos procedimentos de análise. 
Quadro 2 - Fontes de dados e procedimentos de tratamento efetivados no estudo da Revista Engenharia Sanitária e Ambiental.

\begin{tabular}{|l|c|c|}
\hline Fonte de dados & \multicolumn{1}{|c|}{ Dados analisados } \\
\hline $\begin{array}{l}\text { Artigos da Revista Engenharia } \\
\text { Sanitária e Ambiental (PDFs) }\end{array}$ & $\begin{array}{c}\text { Data, título, autores, afiliações, palavras- } \\
\text { chave e resumo }\end{array}$ & $\begin{array}{c}\text { Podos os artigos foram manualmente analisados, produzindo tabela } \\
\text { normalizada com os dados procurados (http://www.scielo.br/scielo) }\end{array}$ \\
\hline Currículos Lattes* & $\begin{array}{c}\text { Nome, Instituição de vínculo profissional } \\
\text { (UF, nome e tipo) Titulação (nível, país/ } \\
\text { UF, ano, curso, área, IES) }\end{array}$ & $\begin{array}{c}\text { Todos os autores tiverem seu Currículo Lattes verificado nos campos } \\
\text { procurados e tabulados na mesma tabela extraída do artigo }\end{array}$ \\
\hline Portal Inovação** & $\begin{array}{c}\text { Palavras-chave, títulos de } \\
\text { produção intelectual }\end{array}$ & $\begin{array}{c}\text { Utilização da ferramenta de buscas do Portal, que permite indexação por } \\
\text { frequência de termos entre os Currículos Lattes e apresenta résumé com } \\
\text { base em informações acadêmicas e profissionais }\end{array}$ \\
\hline Fundos setoriais*** & $\begin{array}{c}\text { Projetos financiados (título, resumo, ano } \\
\text { e recursos) }\end{array}$ & $\begin{array}{c}\text { A base de projetos foi analisada com os mesmos procedimentos de EC } \\
\text { aplicados à base de artigos. }\end{array}$ \\
\hline
\end{tabular}

*Base de currículos da Plataforma Lattes do Conselho Nacional de Desenvolvimento Científico e Tecnológico (CNPq), disponível em consulta pública em seu site de busca textual; **Portal do Ministério da Ciência, Tecnologia e Inovação (MCTI) que permite buscar sobre toda a base de Currículos Lattes atualizados nos últimos 18 meses; ***istema de informação mantido pelo MCTI para consulta aos projetos financiados pelos fundos setoriais; UF: unidade federativa; IES: instituições de ensino superior; EC: engenharia do conhecimento.

Após a preparação dos dados, é possível efetivar os estudos informétricos e aplicar sistemas de conhecimento para análise do universo de atores e temáticas associadas à revista, conforme descrito a seguir.

\section{Procedimentos metodológicos da engenharia do conhecimento}

No método proposto, a descoberta das temáticas tratadas em uma revista ao longo do tempo se dá via ferramenta de identificação de entidades em corpos de texto (unidades de informação descobertas no texto, como cidades, instituições, pessoas (CECI; PIETROBON; GONÇALVES, 2012; CECI et al., 2010). Com isso, foram identificados os termos nos presentes resumos dos artigos da revista (termos empregados na caracterização dos estudos publicados). Para fazer a identificação dos termos neste estudo foi utilizada a ferramenta ISNER ${ }^{\oplus *}$.

Para aplicá-la, o processo implementado é realizado atendendo às seguintes etapas:

1. Reconhecimento dos termos candidatos: nessa etapa são identificados os termos (simples ou compostos) candidatos a termos relevantes, ou a entidades do domínio. Para tal, na ferramenta ISNER ${ }^{\circ}$ é possível selecionar diferentes estratégias para cada tipo de documento. Para este estudo foi utilizada uma abordagem estatística que combina termos em um conjunto de palavras (sete palavras em sequência numa sentença) e os ordena de acordo com a frequência conjunta no documento. Essa estratégia permite identificar termos relevantes, incluindo termos compostos (ex.: "tratamento de esgoto").

2. Validação: essa etapa tem como função analisar as entidades reconhecidas na etapa anterior, de modo a verificar se são representativas (válidas) para o domínio sob análise. Para a validação no âmbito do presente estudo, foi utilizado um glossário criado especificamente

\footnotetext{
${ }^{*}$ A ferramenta ISNER ${ }^{\varpi}$ foi desenvolvida pelo Instituto Stela e permite a descoberta de entidades em textos corridos. Consideram-se "entidades" instâncias (objetos) de categorias de dados gerais que estão registradas no texto. Por exemplo, na frase "O presidente Obama prestou homenagens a Nelson Mandela", há duas instâncias de pessoas ("Obama" e "Nelson Mandela") e uma de político ("presidente Obama").
}

para caracterizar os estudos relacionados à engenharia sanitária e ambiental, de modo que uma entidade é considerada válida caso conste nessa base de termos, ou caso haja um termo relacionado nessa coleção de termos. Para tal, a busca é feita com base no índice textual criado para a coleção de resumos de artigos, em cada período e, quando bem sucedida, tem a entidade encontrada adicionada à lista e marcada como válida.

Para a análise dos textos, os resumos dos artigos foram reunidos de acordo com o ano da edição da revista e separados em triênios, sendo os seguintes estratos: (a) 2004 a 2006; (b) 2007 a 2009; e (c) 2010 a 2011. Os resumos de cada período foram, então, inspecionados com a ferramenta ISNER ${ }^{\odot}$.

Nas seções a seguir, apresenta-se a aplicação do método na análise da Revista ESA.

\section{ANÁLISE DA REVISTA ENGENHARIA SANITÁRIA E AMBIENTAL}

Para analisar a Revista ESA, conforme descrito nas seções a seguir, foram considerados os dados de suas publicações, dos Currículos Lattes de seus autores e de projetos financiados pelos fundos setoriais do MCTI. Os estudos serão contextualizados na cienciometria e na informetria, incluindo a aplicação de sistemas de conhecimento para a análise de dados disponíveis dos artigos e dos projetos financiados pelos fundos setoriais. Na primeira parte, explicitam-se os procedimentos de preparação dos dados do estudo e, posteriormente, os resultados obtidos na análise da Revista ESA.

\section{Análises informétricas} Histórico de publicações

Na Figura 2 estão representadas a cronologia de artigos publicados entre 2004 e 2012 na Revista ESA e a evolução no número médio de autores por artigo a cada ano de publicação. No gráfico da figura estão 
ilustradas as evoluções no total de artigos e de autores e na tabela, além dos números ilustrados no gráfico, apresentam-se as relações de número de autores por artigo, ao longo do tempo.

Durante o período de 8,5 anos analisado, a Revista ESA publicou 333 artigos, com um total de 816 autores e 1.098 autorias (registros de autoria no artigo, incluindo dupla contagem de autores que escrevem mais do que um artigo). Na média, a cada ano a revista registrou um total de 39 artigos escritos por 96 autores (retirada a dupla contagem de autores com mais de uma autoria e um único vínculo institucional). Em relação ao seu perfil histórico, o ano de 2009 se diferencia pelo aumento no número médio de artigos publicados (de 39 para 52), indicando mais espaço de registro e difusão de conhecimentos produzidos. O ano de 2012 também se diferencia em função do aumento na média de autores por artigo (da média histórica de 3,2 para 3,8), indicando mais colaboração na produção de conhecimentos.

\section{Perfil temático (via palavras-chave) e contexto no sistema de ciência, tecnologia e inovação brasileiro}

A análise das palavras-chave permite verificar o perfil de temas publicados pela revista ao longo de sua cronologia. No estudo da Revista ESA, durante os 8,5 anos de publicações analisados, os autores utilizaram um total de 979 palavras-chave. Em relação à frequência de ocorrências, verificou-se uma ampla dispersão no número de vezes com que cada

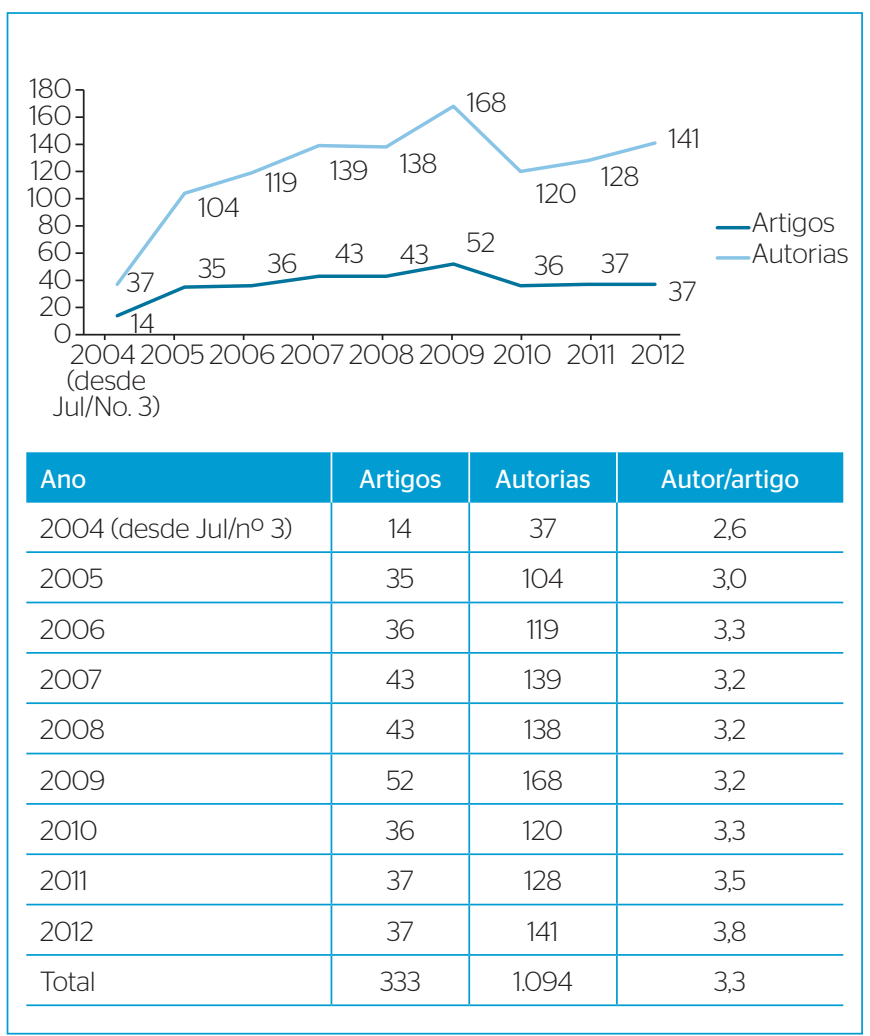

Figura 2 - Cronologia das publicações na Revista Engenharia Sanitária e Ambiental. termo foi utilizado. Essa dispersão pode ser exemplificada com a análise das palavras que representam $11 \%$ das ocorrências no total dos artigos publicados. Esse subconjunto corresponde a palavras que foram atribuídas a 16 artigos ( $1,13 \%$ do total) e 6 artigos ( $0,43 \%$ do total), ao longo da história da revista. Tratam-se dos termos: "qualidade da água" (16 vezes), “saneamento" (16 vezes), "tratamento de água" (16 vezes), "metais pesados" (10 vezes), "resíduos sólidos urbanos" (9 vezes), "tratamento de esgoto" (9 vezes), "aterro sanitário" (8 vezes), "lodo ativado" (8 vezes), "abastecimento de água” (7 vezes), "esgoto doméstico" (7 vezes), "esgoto sanitário" (7 vezes), "lixiviado" (7 vezes), "reuso da água” (7 vezes), “adsorção” (6 vezes), “indicadores" (6 vezes), "resíduos sólidos” (6 vezes), "saúde ambiental" (6 vezes) e "tratamento anaeróbico" (6 vezes).

Diante dessa variedade de termos, foi solicitado a dois especialistas nas áreas de engenharia sanitária e ambiental que classificassem as palavras-chave em categorias, ou seja, em temáticas que agregam os diversos temas utilizados pelos autores para classificarem suas pesquisas. Na Tabela 1 estão apresentadas as categorias e o número de ocorrências de palavras-chave em cada uma dessas categorias.

Para a escolha dos especialistas, foram levadas em consideração sua atuação em programas de pós-graduação e sua experiência profissional na temática ambiental e sanitária, além de sua experiência editorial científica nessas temáticas.

Em síntese, com relação à classificação do conhecimento registrado na Revista ESA, pode-se concluir que há uma dispersão de temas apontados por seus autores, cujas classificações no domínio de conhecimentos de interesse da revista permitem evidenciar 14 classes de temáticas. Dessas, "sistema de esgotamento sanitário", "qualidade ambiental", "metodologia", "política e gestão ambiental" e "tratamento de água" classificam $64 \%$ do total de termos utilizados.

Tabela 1 - Distribuição das palavras-chave dos artigos na Revista Engenharia Sanitária e Ambiental em categorias de termos.

\begin{tabular}{l|c|c}
\hline Categoria & Palavras-chave & $\%$ \\
\hline Sistema de esgotamento sanitário & 167 & 17 \\
\hline Qualidade ambiental & 155 & 16 \\
\hline Metodologia & 129 & 13 \\
\hline Política e gestão ambiental & 99 & 10 \\
\hline Tratamento de água & 78 & 8 \\
\hline Política e gestão em saneamento & 69 & 7 \\
\hline Resíduos sólidos & 65 & 7 \\
\hline Recursos hídricos & 51 & 5 \\
\hline Saúde pública & 49 & 5 \\
\hline Tratamento de efluentes industriais & 30 & 3 \\
\hline Sistema de abastecimento de água & 27 & 3 \\
\hline Lodo de estações de tratamento & 26 & 3 \\
\hline Recuperação de áreas degradadas & 20 & 2 \\
\hline Poluição atmosférica & 14 & 1 \\
\hline Total & 979 & 100 \\
\hline
\end{tabular}


O principal objetivo em se analisar fatores como palavras-chave ou categorias é explicitar o conteúdo produzido na revista científica. Essas análises permitem, também, que se realizem comparações entre o que se publica na revista e o contexto geral de suas temáticas em um sistema de CT\&I. Pode-se verificar, por exemplo, qual é o grau de cobertura de temas que a Revista ESA representa sobre os domínios das ciências ambientais e da engenharia sanitária. Neste estudo, essa comparação se deu por meio da realização de buscas no Portal Inovação do MCTI (www.portalinovacao. mcti.gov.br), registrando-se o número de pessoas que têm essas mesmas categorias de palavras-chave em seus currículos. Para tal, foram pesquisadas as presenças nos Currículos Lattes das seis categorias mais frequentes na Revista ESA, por corresponderem a 71\% do total de palavras-chave da Revista. O resultado dessa consulta está apresentado na Tabela 2.

Buscas no Portal Inovação incluem, entre os resultados, o cálculo de co-ocorrências de palavras-chave. Além disso, além dos Currículos Lattes, o Portal inclui portfólios de especialistas que não possuem currículo, mas que registram projetos em suas experiências profissionais. Em relação ao Lattes, a amostra de busca se refere, no Portal Inovação, aos Currículos Lattes atualizados nos últimos 18 meses.
Conforme se pode ver na Tabela 2, as categorias de termos utilizados nos artigos da Revista ESA estão presentes em milhares de Currículos Lattes no País. As categorias "qualidade ambiental" e "metodologia + 'gestão ambiental"' são as mais frequentes, com 5.495 e 5.493 currículos, respectivamente. Considerando-se, no entanto, os dez primeiros especialistas com o maior número de vezes com esses termos presentes em seus currículos, é nas categorias "tratamento de água" e "política e gestão em saneamento" que os autores da Revista ESA mais se destacam, com 9 entre 10 e 4 entre 10 especialistas, respectivamente. Portanto, em temáticas mais gerais em que trabalham especialistas do país, a proporção de participação dos autores da Revista ESA é menor. Por outro lado, naquelas mais específicas ao interesse da disciplina, ocorre o inverso.

Uma segunda forma de se verificar a aderência dos temas tratados na Revista ESA com as pesquisas no sistema brasileiro de CT\&I se dá por comparação entre as palavras-chave dos artigos da revista e os termos mais frequentes nos currículos da Plataforma Lattes. Essa comparação está ilustrada na Tabela 3.

$\mathrm{Na}$ Tabela 3 apresentam-se os termos mais frequentes encontrados nos cem primeiros Currículos Lattes de especialistas atuando nas

Tabela 2 - Presença de conteúdos da engenharia sanitária e ambiental em currículos do Sistema Nacional de Ciência, Tecnologia e Inovação do país (por titulação).

\begin{tabular}{|c|c|c|c|c|c|c|c|c|c|c|c|}
\hline \multirow{2}{*}{ No } & \multirow{2}{*}{$\begin{array}{l}\text { Palavras-chave nos artigos } \\
\text { Da } 1^{\mathrm{a}} \text { à } 6^{\mathrm{a}} \text { mais frequente }\end{array}$} & \multicolumn{3}{|c|}{ Ocorrências } & \multicolumn{6}{|c|}{ Total de Currículos Lattes com a palavra-chave } & \multirow{2}{*}{$\begin{array}{l}\text { Autores } \\
\text { entre } 10\end{array}$} \\
\hline & & Frequência & $\%$ & $\%$ acumulada & Doutores & Mestres & Especialistas & Graduados & Outros & Total & \\
\hline 1 & Sistema de esgotamento sanitário & 167 & 23,9 & 23,9 & 167 & 107 & 40 & 48 & 14 & 376 & 2 \\
\hline 2 & Qualidade ambiental & 155 & 22,2 & 46,1 & 2.779 & 1.438 & 288 & 597 & 393 & 5.495 & $\mathrm{O}$ \\
\hline 3 & Metodologia (e "gestão ambiental") & 129 & 18,5 & 64,6 & 3.383 & 1.562 & 241 & 226 & 81 & 5.493 & 1 \\
\hline 4 & Política e gestão ambiental & 99 & 14,2 & 78,8 & 55 & 27 & 3 & 2 & 1 & 88 & 1 \\
\hline 5 & Tratamento de água & 78 & 11,2 & 90,0 & 1.855 & 924 & 228 & 405 & 248 & 3.660 & 9 \\
\hline 6 & Política e gestão em saneamento & 69 & 9,9 & 99,9 & 10 & 1 & $\mathrm{O}$ & 2 & 1 & 14 & 4 \\
\hline
\end{tabular}

Fonte dos Dados: Portal Inovação (www.portalinovacao.mct.gov.br)

Tabela 3 - Presença das palavras-chave mais frequentes nos artigos da Revista Engenharia Sanitária e Ambiental em currículos do Sistema Nacional de Ciência, Tecnologia e Inovação do país (por frequência nos currículos).

\begin{tabular}{|c|c|c|c|c|c|c|}
\hline \multirow{2}{*}{ No } & \multirow{2}{*}{$\begin{array}{l}\text { Palavras-chave nos artigos } \\
\text { Da } 1^{\mathrm{a}} \text { à } 6^{\mathrm{a}} \text { mais frequente }\end{array}$} & \multicolumn{5}{|c|}{ Palavras-chave mais frequentes nos Currículos Lattes } \\
\hline & & \multirow{2}{*}{$\begin{array}{l}\text { Palavra-chave } 1 \\
\text { Saneamento }\end{array}$} & Palavra-chave 2 & Palavra-chave 3 & Palavra-chave 4 & Palavra-chave 5 \\
\hline 1 & $\begin{array}{c}\text { Sistema de esgotamento } \\
\text { sanitário }\end{array}$ & & Água & Saneamento básico & $\begin{array}{l}\text { Saneamento } \\
\text { ambiental }\end{array}$ & Saúde \\
\hline 2 & Qualidade ambiental & Peixes & Clima & Educação ambiental & Conservação & Clima urbano \\
\hline 3 & $\begin{array}{c}\text { Metodologia (e "gestão } \\
\text { ambiental") }\end{array}$ & Microbacia & Adequação Ambiental & Propriedades rurais & $\begin{array}{l}\text { Desenvolvimento } \\
\text { Sustentável }\end{array}$ & Meio Ambiente \\
\hline 5 & Tratamento de água & Água & Flitração & Flotação & Lodos & Águas residuárias \\
\hline 6 & Política e gestão em saneamento & Saneamento & $\begin{array}{l}\text { Saneamento } \\
\text { ambiental }\end{array}$ & Saneamento básico & Saúde & Gestão \\
\hline
\end{tabular}

\begin{tabular}{|c|c|c|}
\hline 1 a 2 ocorrências & 5 a 6 ocorrências & 9 a 10 ocorrências \\
\hline 3a 4 ocorrências & 7 a 8 ocorrências & Mais de 10 ocorrências
\end{tabular}


temáticas de publicação da Revista ESA. Para a área de "sistema de esgotamento sanitário", por exemplo, nos 376 currículos (conforme Tabela 2), os 100 primeiros trazem essa expressão em alguma produção intelectual concomitante com as palavras-chave "saneamento", "água", "saneamento básico", "saneamento ambiental" e "saúde" (em ordem decrescente de ocorrências nos currículos). Dessas, a palavra "saneamento" é a que mais ocorre também entre os artigos publicados na Revista ESA (com 16 ocorrências em artigos na Revista ESA), seguido de "saneamento ambiental" (com 5 ocorrências em artigos na Revista ESA).

Cabe salientar que a busca no Portal Inovação retorna especialistas em ordem decrescente do número de vezes que o termo procurado aparece em cada currículo. Isso significa que os cem primeiros são aqueles que têm o maior número de vezes mencionada a expressão utilizada na busca. Não há, portanto, relação com produtividade ou com avaliação qualitativa dos especialistas.

Os hachurados na Tabela 3 representam o grau de aderência entre as frequências dos termos nos currículos e as palavras-chave na revista. Assim, se todos os termos mais frequentes nos Currículos Lattes tivessem uma frequência acima de dez vezes na revista, todas as células da matriz teriam fundo escuro. Quanto mais clara for a cor da matriz apresentada na Tabela 3, menor a relação entre as frequências de termos na revista e nos currículos de pessoas atuantes nas temáticas de interesse da revista.

Há um total de 21 termos encontrados nos Currículos Lattes relacionados aos termos presentes na Revista ESA. Desses, 4 ocorrem mais de 10 vezes na revista ("filtração", "gestão", "lodos" e "saneamento"), 2 ocorrem 5 vezes ("águas residuárias" e "saneamento ambiental"), 1 ocorre 3 vezes ("flotação") e as demais, menos de 3 vezes. Os termos de baixa distribuição de frequências na Revista ESA são ou gerais (ex.: "clima" ou "clima urbano", "educação ambiental", "desenvolvimento sustentável") ou ligados a temas específicos em outras áreas do conhecimento (ex.: "peixes").

\section{Distribuição de autorias}

A segunda análise realizada na Revista ESA diz respeito ao perfil de autores e de autorias entre os artigos publicados no período do estudo. Na Tabela 4 apresentam-se as distribuições de autorias em todo o histórico da Revista ESA. As três primeiras colunas da tabela se referem à análise de coautorias, considerando cada autor e suas diferentes participações na Revista ESA. Nessa análise, 1 autor participou em 17 autorias de artigos (i.e., é autor de 17 artigos, individual ou coletivamente) e 641 autores participaram de apenas 1 autoria (i.e., foram autores em apenas 1 artigo). As três últimas colunas da tabela analisam a autoria sob a visão dos artigos publicados. Há 1 artigo com 8 autores (representando 8 coautorias no total da revista) e 109 artigos com 2 autores (representando 218 coautorias no total da revista).
Como se pode verificar na Tabela 4, entre julho de 2004 e dezembro de 2012, a Revista ESA publicou um total de 333 artigos, escritos por 798 autores (o número de 816 apresentado na Figura 3 e inclui pessoas com 2 afiliações institucionais, 1 para cada data de publicação do artigo), que assinaram um total de 1.094 autorias (ou seja, houve 1.094 associações autor-artigo). Nesse período, houve um autor que publicou 17 artigos (com e sem coautoria) e 641 pessoas que publicaram um único artigo na revista. Por outro lado, o número máximo de autores ocorreu em 1 artigo com 8 autorias, sendo que a maioria dos artigos da revista têm 2 ou 3 autores ( 211 dos 333 artigos). Nesse período, a revista teve médias de 3,29 autores por artigo e de 0,7 artigos por autor. Esses números indicam que os artigos são resultantes de trabalhos coletivos (dado que a média é acima de três autores por artigo) e de que não há

Tabela 4 - Perfil de autorias e de número de autores por artigo na Revista Engenharia Sanitária e Ambiental.

\begin{tabular}{l|c|c|c|c|c}
$\begin{array}{l}\text { No de } \\
\text { autores }\end{array}$ & Autorias & $\begin{array}{c}\text { Total de } \\
\text { autorias }\end{array}$ & $\begin{array}{c}\text { No de } \\
\text { artigos }\end{array}$ & $\begin{array}{c}\text { No de } \\
\text { autores }\end{array}$ & $\begin{array}{c}\text { Total de } \\
\text { autorias }\end{array}$ \\
\hline 1 & 17 & 17 & 1 & 8 & 8 \\
\hline 1 & 13 & 13 & 5 & 1 & 5 \\
\hline 1 & 10 & 10 & 6 & 7 & 42 \\
\hline 2 & 9 & 9 & 19 & 6 & 114 \\
\hline 3 & 8 & 16 & 38 & 5 & 190 \\
\hline 4 & 5 & 18 & 52 & 4 & 208 \\
\hline 13 & 4 & 52 & 109 & 2 & 309 \\
\hline 36 & 3 & 108 & - & - & - \\
\hline 95 & 2 & 190 & - & - & - \\
\hline 641 & 1 & 641 & - & - & - \\
\hline 798 & - & 1094 & 333 & & 1094 \\
\hline \multicolumn{7}{l|}{ Média de autorias } & 0,73 & Média de autores/artigo & 3,29 \\
\hline
\end{tabular}

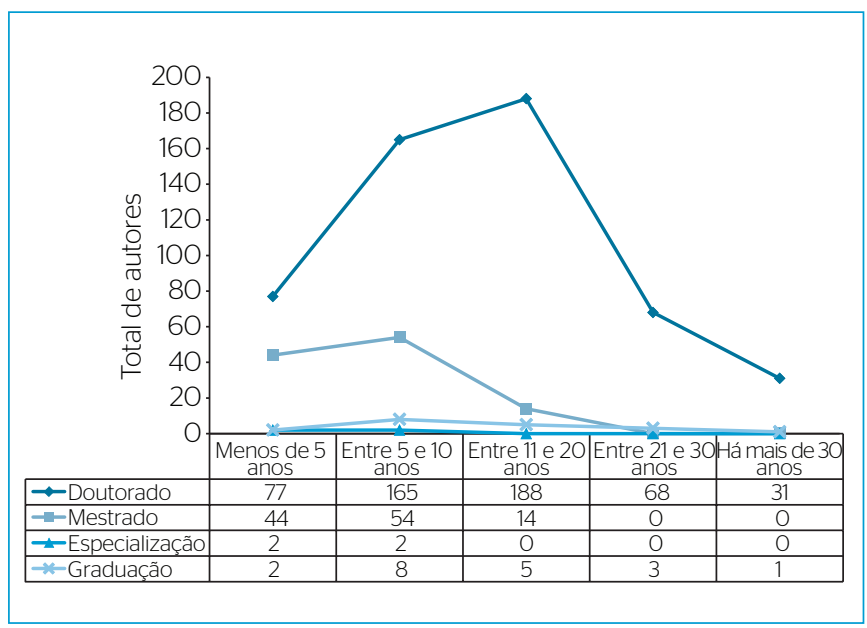

Figura 3 - Distribuição do tempo de titulação dos autores da Revista Engenharia Sanitária e Ambiental. 
concentração das publicações sobre um universo de autores (dado que a média de artigos por autor é inferior a um).

\section{Perfil dos autores (atuação profissional)}

A terceira análise útil para se conhecer o universo de autores da revista se refere à origem institucional das pessoas que nela publicam. No estudo realizado, há duas fontes de informação capazes de responder a essa questão: a afiliação explicitada no artigo e a afiliação registrada no Currículo Lattes, à época do estudo. Na Tabela 5 apresentam-se os tipos de instituições de vínculos dos 816 autores que publicaram artigos no período da análise, considerando-se tanto o vínculo descrito na revista como o constado nos Currículos Lattes.

Como se pode verificar na Tabela 5 , a maioria dos autores que publicam na Revista ESA é oriunda do setor acadêmico e, mais precisamente, de universidades públicas (69\% quando publicaram o artigo e 56\% conforme vinculação atual no Currículo Lattes). A diferença entre os perfis em cada forma de vinculação se deve, principalmente, a dois fatores:

1. distinção entre os tempos de registro de vínculo (a informação da revista é referente ao tempo da última publicação do autor e a do currículo de seu vínculo informado na data deste estudo); e
2. diferença de disponibilidade de dados (há um total de 52 autores sem Currículo Lattes, além de currículos sem informação de vínculo - 62 currículos).

Entre as outras organizações de vínculo dos autores da revista, registram-se empresas (entre 5 e 9\%), instituições estrangeiras (cerda de $2 \%$ na vinculação do artigo e de $1 \%$ no currículo), além de organizações governamentais e institutos.

\section{Perfil dos autores (titulação)}

Em sua maioria, as revistas científicas costumam não publicar a titulação dos autores dos artigos. Com a vinculação da base nacional de currículos, no entanto, essa informação pode ser agregada, permitindo uma análise do perfil dos autores segundo a titulação máxima das pessoas que publicaram na revista (quanto à instituição de origem, ao ano da titulação, ao nível e à área de conhecimento do curso em que foi titulado).

No caso da Revista ESA, conforme se pode verificar na Tabela 6, do total de autores, $87 \%$ têm pós-graduação. Desses, $65 \%$ são doutores, $6 \%$ estão cursando o doutorado, $16 \%$ são mestres e $2 \%$ estão cursando o

Tabela 5 - Tipo de instituições de vínculo dos autores da Revista Engenharia Sanitária e Ambiental.

\begin{tabular}{l|c|c}
\hline Classificação por afiliação no artigo & Total & $\%$ \\
\hline Universidade pública federal & 343 & 42,0 \\
\hline Universidade pública estadual & 222 & 27,2 \\
\hline Universidade privada & 60 & 7,4 \\
\hline Instituto federal & 33 & 4,0 \\
\hline Empresa privada & 25 & 3,1 \\
\hline Empresa pública & 20 & 2,5 \\
\hline Instituição de ciência, tecnologia e inovação pública & 15 & 1,8 \\
\hline Universidade comunitária & 14 & 1,7 \\
\hline Instituto de pesquisa & 13 & 1,6 \\
\hline Universidade estrangeira & 13 & 1,6 \\
\hline Centro de pesquisa & 8 & 1,0 \\
\hline Faculdade & 7 & 0,9 \\
\hline Instituto estadual & 5 & 0,6 \\
\hline Instituto estrangeiro & 5 & 0,6 \\
\hline Não informado & 5 & 0,6 \\
\hline Agência de fomento federal & 4 & 0,5 \\
\hline Consultor & 2 & 0,2 \\
\hline Escola Técnica & 2 & 0,2 \\
\hline Prefeitura municipal & 2 & 0,2 \\
\hline Secretaria municipal & 2 & 0,2 \\
\hline Autarquia federal & 14 & 1,7 \\
\hline Outro & 816 & 100 \\
\hline Total & & \\
\hline & 2 & \\
\hline
\end{tabular}

\begin{tabular}{l|c|c}
\hline Classificação por vínculo no Currículo Lattes & Total & $\%$ \\
\hline Universidade pública federal & 289 & 35,42 \\
\hline Universidade pública estadual & 174 & 21,32 \\
\hline Instituto federal & 48 & 5,88 \\
\hline Universidade privada & 42 & 5,15 \\
\hline Empresa privada & 41 & 5,02 \\
\hline Empresa pública & 32 & 3,92 \\
\hline Instituto de pesquisa & 12 & 1,47 \\
\hline Fundação & 8 & 0,98 \\
\hline Instituição de ciência, tecnologia e inovação pública & 8 & 0,98 \\
\hline Universidade comunitária & 8 & 0,98 \\
\hline Faculdade & 7 & 0,86 \\
\hline Universidade estrangeira & 7 & 0,86 \\
\hline Prefeitura municipal & 6 & 0,74 \\
\hline Governo & 5 & 0,61 \\
\hline Centro de pesquisa & 4 & 0,49 \\
\hline Escola pública & 3 & 0,37 \\
\hline Instituto estadual & 3 & 0,37 \\
\hline Associação privada & 1 & 0,12 \\
\hline Escola privada & 1 & 0,12 \\
\hline Holding & 1 & 0,12 \\
\hline Instituto privado & 1 & 0,12 \\
\hline Secretaria municipal & 1 & 0,12 \\
\hline Não informado & 816 & 13,97 \\
\hline Total & & 100 \\
\hline & & \\
\hline
\end{tabular}


mestrado. Como se verifica na Figura 3, a maioria dos doutores (35\%) concluiu seu doutorado entre 11 e 20 anos atrás, enquanto a maioria dos mestres (48\%) obteve seu título entre 5 e 10 anos atrás.

Em síntese, percebe-se a participação tanto de doutores experientes como de jovens pesquisadores entre os autores da Revista ESA. Outro aspecto elucidativo sobre seu universo de escritores surge quando são verificadas as Instituições de Ensino Superior (IES) de origem de titulação desses autores. Nas Tabelas 7 e 8 estão apresentados dados referentes às IES de titulação máxima dos autores da Revista ESA.

Como se pode ver, a ampla maioria dos autores da revista (71\%) obteve sua titulação máxima no país, em universidades públicas, de nível federal ou estadual. Ao todo, os autores da Revista ESA se

Tabela 6 - Nível de titulação dos autores da Revista Engenharia Sanitária e Ambiental.

\begin{tabular}{l|c|c}
\hline Titulação & Total & $\%$ \\
\hline Doutorado & 52965 & \\
\hline Mestrado & 112 & 14 \\
\hline Não informado & 49 & 6 \\
\hline Doutorado em andamento & 48 & 6 \\
\hline Graduação em andamento & 34 & 4 \\
\hline Graduação & 19 & 2 \\
\hline Mestrado em andamento & 19 & 2 \\
\hline Especialização & 4 & 0 \\
\hline Especialização em andamento & 1 & 0 \\
\hline Técnico & 1 & 0 \\
\hline Total & 816 & 100 \\
\hline
\end{tabular}

Tabela 7 - Tipo de instituição de ensino superior de titulação máxima dos autores da Revista Engenharia Sanitária e Ambiental.

\begin{tabular}{l|c|c}
\hline Instituição de ensino superior de titulação & Total & $\%$ \\
\hline Universidade pública federal & 301 & $37 \%$ \\
\hline Universidade pública estadual & 293 & $36 \%$ \\
\hline Universidade estrangeira & 102 & $13 \%$ \\
\hline (vazio) & 47 & $6 \%$ \\
\hline Universidade privada & 28 & $3 \%$ \\
\hline Universidade pública & 18 & $2 \%$ \\
\hline Instituto de pesquisa & 9 & $1 \%$ \\
\hline Instituto federal & 6 & $1 \%$ \\
\hline Faculdade & 5 & $1 \%$ \\
\hline NÃO INFORMADO & 3 & $0 \%$ \\
\hline Centro de pesquisa & 1 & $0 \%$ \\
\hline Empresa privada & 1 & $0 \%$ \\
\hline Escola privada & 1 & $0 \%$ \\
\hline Fundação de Amparo à Pesquisa & 1 & $0 \%$ \\
\hline Total Geral & 816 & $100 \%$ \\
\hline
\end{tabular}

titularam em 170 instituições de ensino diferentes, sendo que as instituições com o maior número de autores titulados são: Universidade de São Paulo - USP (26\%); Universidade Federal de Minas Gerais UFMG (7\%); Universidade Federal de Santa Catarina - UFSC (5\%); Universidade Federal do Rio Grande do Sul - UFRGS (5\%); Universidade Federal do Ceará - UFC (4\%); Universidade Estadual de Campinas UNICAMP (4\%); Universidade Estadual de São Paulo - UNESP (3\%); Universidade Federal de Viçosa - UFV (3\%); Universidade Federal do Rio de Janeiro - UFRJ (2\%); Universidade Federal do Paraná UFPR (2\%); e Universidade Federal de São Carlos - UFSCar (2\%).

Na Figura 4 estão apresentadas as áreas de titulação máxima dos autores da Revista ESA. Uma das características observadas é a diversidade de formações, envolvendo engenharias, ciências agrárias e biológicas, ciências da saúde e administração pública. O perfil de formações também revela áreas emergentes, de natureza multidisciplinar, que começam a formar os primeiros titulados, como desenvolvimento sustentável. As áreas com o maior número de autores titulados são as engenharias sanitária e civil, com $9 \%$ do total de autores cada uma. A gama de formações dos autores indica uma tendência à multidisciplinaridade nas temáticas da Revista ESA.

\section{Mobilidade dos autores (titulação e atuação profissional)}

Um dos fatores relevantes no processo de desenvolvimento de sistemas de CT\&I diz respeito à mobilidade de especialistas, tanto em seu período de formação como de fixação profissional. Com as informações coletadas sobre os currículos dos autores da Revista ESA, foi possível comparar as instituições de formação (tempo da titulação) com as instituições de vínculo no endereço profissional do currículo (tempo atual). Isso produz uma "matriz de mobilidade" dos autores da revista, com comparações entre o estado de destino e o estado origem das instituições de vínculo e de titulação. Para tal, basta comparar o endereço de formação com o de vínculo profissional. O total

Tabela 8 - Instituições de ensino superior de titulação máxima dos autores da Revista Engenharia Sanitária e Ambiental.

\begin{tabular}{l|c|c}
\hline Instituição de ensino superior de titulação & Total & $\%$ \\
\hline Universidade de São Paulo & 212 & 26 \\
\hline Universidade Federal de Minas Gerais & 57 & 7 \\
\hline (vazio) & 47 & 6 \\
\hline Universidade Federal de Santa Catarina & 39 & 5 \\
\hline Universidade Federal do Rio Grande do Sul & 38 & 5 \\
\hline Universidade Federal do Ceará & 36 & 4 \\
\hline Universidade de Campinas & 34 & 4 \\
\hline Universidade Estadual Paulista “Júlio de Mesquita Filho” & 24 & 3 \\
\hline Universidade Federal de Viçosa & 22 & 3 \\
\hline Universidade Federal do Rio de Janeiro & 18 & 2 \\
\hline Universidade Federal do Paraná & 16 & 2 \\
\hline Universidade Federal de São Carlos & 14 & 2 \\
\hline
\end{tabular}




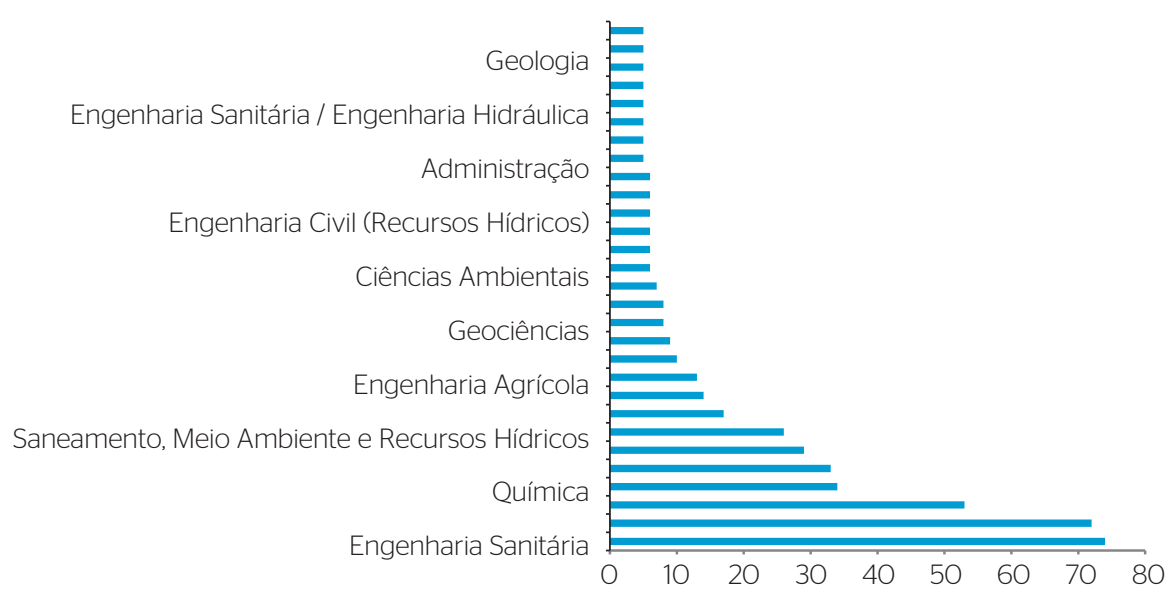

Figura 4 - Distribuição das áreas de formação dos autores da Revista Engenharia Sanitária e Ambiental (áreas com quatro autores no mínimo).

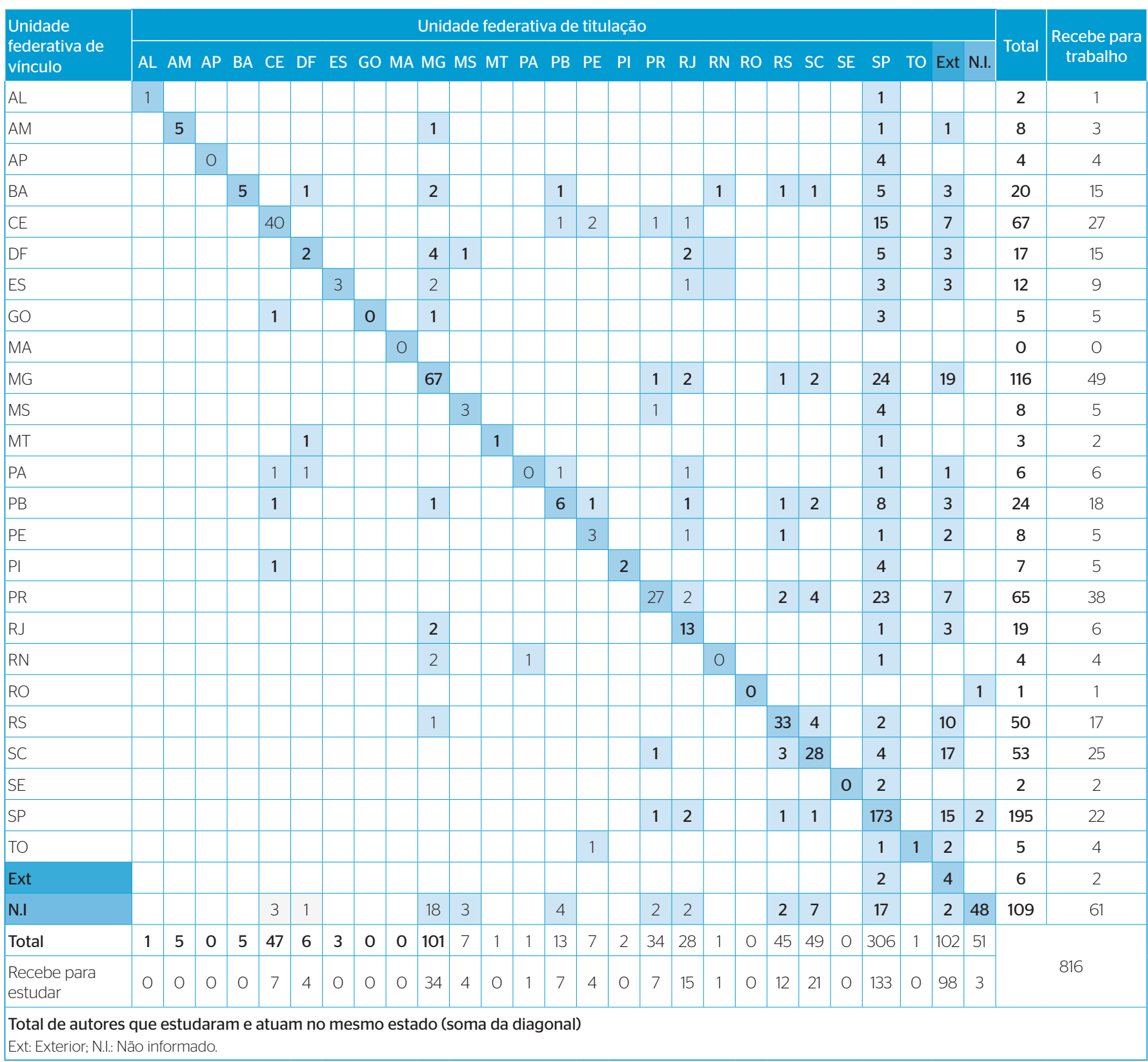

Figura 5 - Matriz de mobilidade entre formação e atuação profissional dos autores residentes no país. 
de autores que se titularam e que trabalham no mesmo estado (ou no exterior) estarão indicados na diagonal da matriz. Nas demais células aparecerão os cruzamentos de mobilidade entre os estados de titulação e de trabalho dos autores. Assim, a revista funciona como uma "lente" que permite verificar fluxos entre lugares que oferecem oportunidades de formação e de trabalho, no domínio de educação e atuação profissional dado pelas temáticas de publicação da revisa. No caso da Revista ESA, essa "lente" está apresentada na Figura 5.

A matriz de mobilidade representada na Figura 5 pode ser analisada sob a ótica das oportunidades regionais de formação (colunas) ou de trabalho (linhas). No caso dos 816 autores da Revista ESA, há um total de 413 autores que têm tanto sua formação como sua vinculação no mesmo estado (somatório da diagonal da matriz chega a 51\% do total de autores). Desses, São Paulo é o estado que mais formou e manteve vinculados profissionalmente autores da revista (173 pessoas), seguido de Minas Gerais (67), Ceará (40), Rio Grande do Sul (33) e Santa Catarina (28).

Além de permitir comparar os estados formadores e retentores de pessoas, a matriz de mobilidade permite verificar a capacidade de atração de pessoas das regiões, tanto por ofertarem formação como trabalho nas temáticas de publicação da revista. A análise da Revista ESA permite verificar que são mais formadores os seguintes estados: São Paulo (que titulou 133 autores vinculados a outros estados), Minas Gerais (34 autores titulados), Santa Catarina (21 autores titulados) e Rio de Janeiro (15 autores titulados).

O terceiro aspecto de comparabilidade regional ofertado pela matriz de mobilidade diz respeito à oferta profissional nos campos de conhecimento relacionados à revista. Nesse caso, supõe-se que os vínculos profissionais dos autores, declarados em seus currículos, guardem relação com as temáticas de conhecimento que a revista divulga. No caso da Revista ESA, verifica-se a seguinte classificação para os estados brasileiros enquanto ofertantes de trabalho a pessoas tituladas em outros estados: Minas Gerais (com 49 autores), Paraná (38), Ceará (27), Santa Catarina (25) e São Paulo (22).

Quando a matriz de mobilidade inclui a titulação e a formação fora do país, permite, também, fazer as análises acima para regiões estrangeiras, tanto como ofertantes de titulação como de oportunidade profissional para campos do conhecimento relacionados à proposta da revista. No caso da Revista ESA, percebe-se que há 98 autores que estudaram no exterior e 2 autores vinculados profissionalmente a organizações no exterior que estudaram no Brasil.

\section{Análises segundo a Engenharia do Conhecimento}

Nesta seção, apresentam-se os procedimentos contextualizados no âmbito da engenharia do conhecimento aplicados sobre os dados da Revista ESA, aplicados tanto sobre os artigos publicados como sobre uma base de financiamentos em CT\&I (fundos setoriais do MCTI).

Para tal, adotou-se abordagem alternativa à descrita na seção Perfil Temático (via palavras-chave). Foram aplicadas técnicas da engenharia do conhecimento sobre os resumos dos artigos, com vistas a extrair tópicos recorrentes diretamente do texto das publicações. Essa abordagem foi feita visando ampliar o conjunto de análise das temáticas produzidas da revista e, ao final, são analisados projetos que receberam fomento no sistema federal no âmbito das temáticas tratadas.

\section{Análise de frequência de termos}

Conforme ilustra a Figura 6, os trabalhos publicados nas edições do período 2004 a 2006 enfocaram principalmente as temáticas "qualidade ambiental" e "tratamento de esgoto". Nesse período, a temática

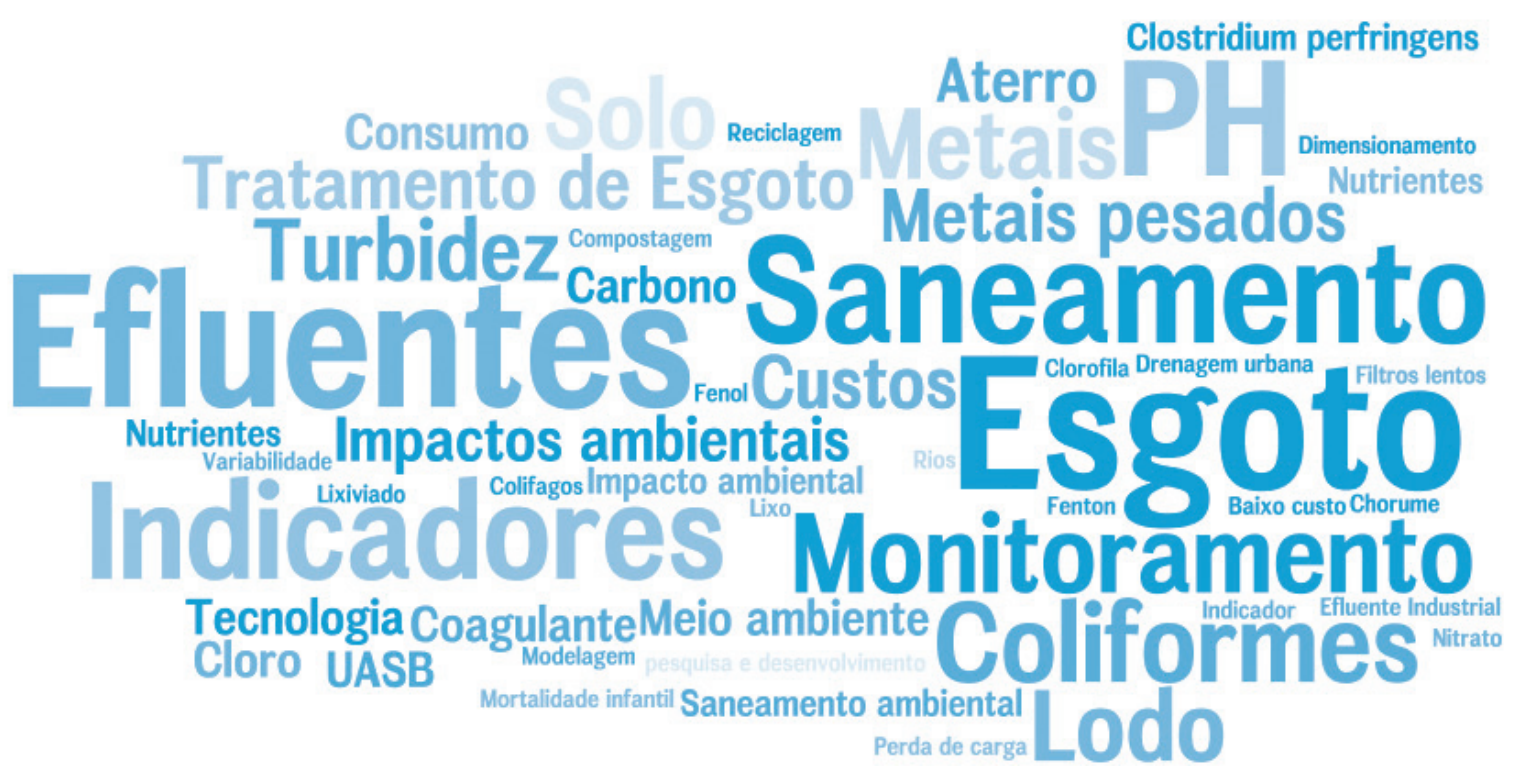

Figura 6 - Termos mais frequentes nas edições de 2004 a 2006. 
"qualidade ambiental" é caracterizada por pesquisas relacionadas a temas como saneamento, indicadores, estratégias de monitoramento e análise do solo. Já na temática "tratamento de esgoto", são enfatizadas técnicas para o tratamento, efluentes, reatores UASB e fatores como coliformes e lodo.

Conforme ilustra a Figura 7, nos anos seguintes, entre 2007 e 2009, as pesquisas continuaram concentradas nas temáticas "qualidade ambiental" e "tratamento de esgoto". A temática "qualidade ambiental" continua enfatizando indicadores e estratégias de monitoramento, mas pesquisas remetendo a elementos como carbono e nitrato ganham maior ênfase. A temática "tratamento de esgoto" continua envolvendo técnicas para o tratamento, efluentes e reatores UASB, mas pesquisas sobre metano e biodegradabilidade passam a ganhar mais espaço. Destacam-se nesse período as pesquisas sobre estações de tratamento, saneamento e lodo.

Finalmente, conforme ilustrado na Figura 8, nas edições realizadas entre 2010 e 2011, verificou-se que uma ênfase ainda maior nas temáticas "tratamento de esgotos" e "qualidade ambiental". Nesse período,

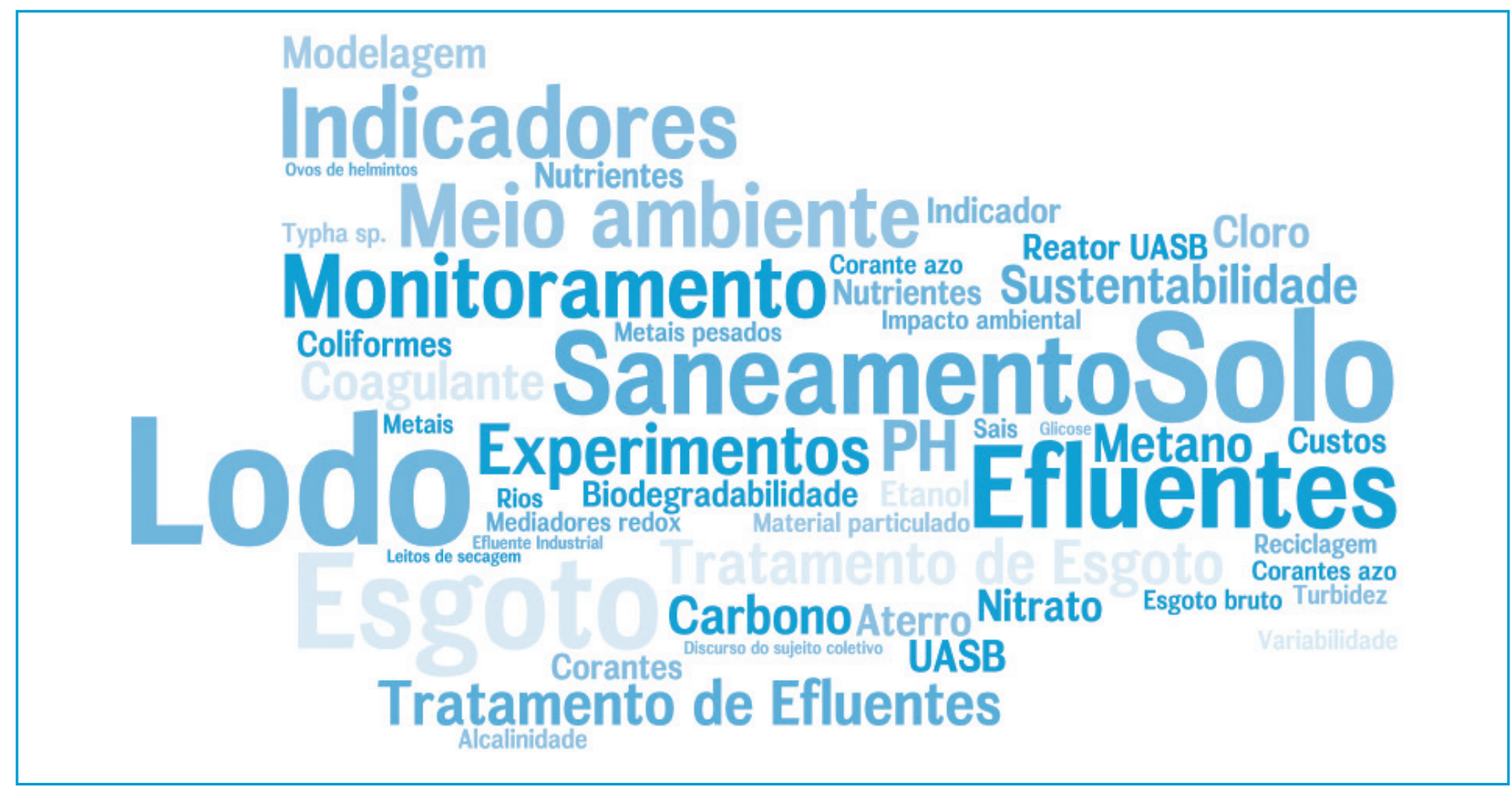

Figura 7 - Termos mais frequentes nas edições de 2007 a 2009.

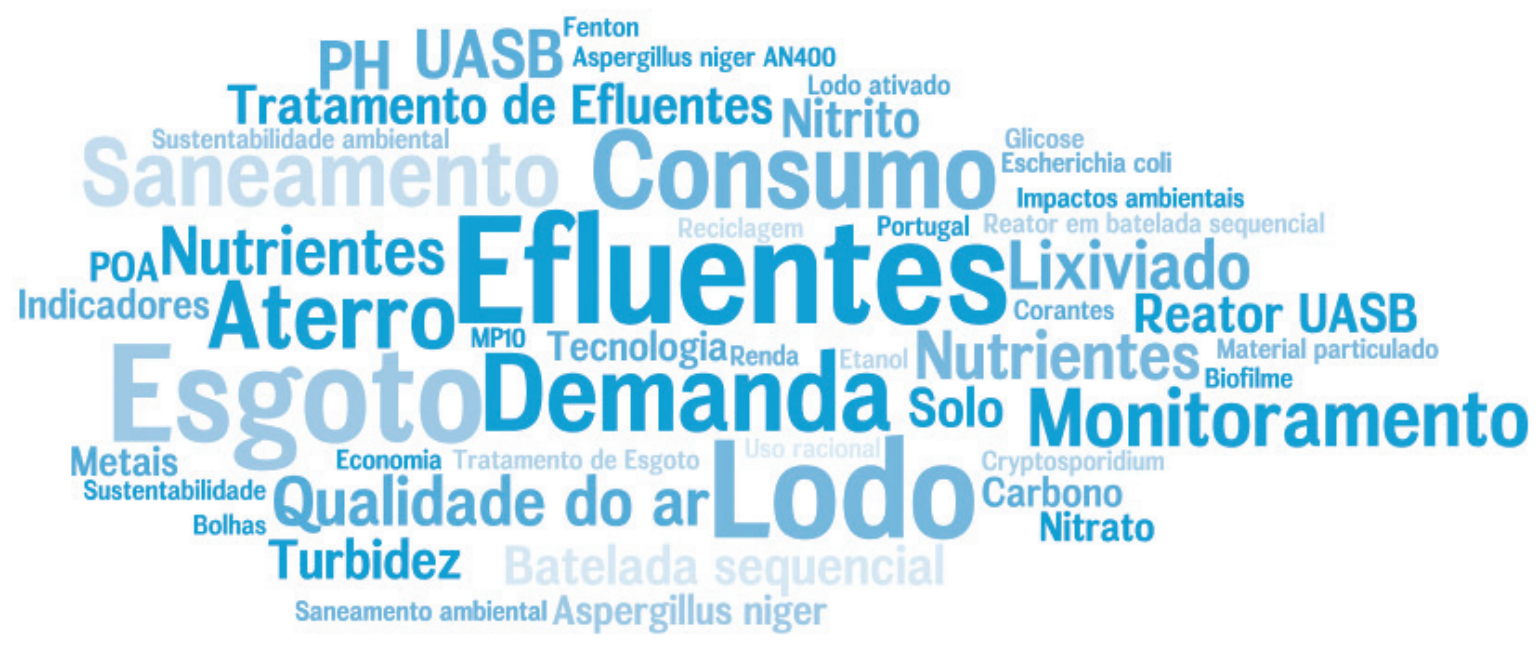

Figura 8 - Termos mais frequentes nas edições de 2010 a 2011. 
nos artigos sobre "qualidade ambiental" surgiram temas como economia e renda e ênfases à qualidade do ar, ao consumo (de água) e à análise de efeitos sobre nutrientes do solo. Nesse período é registrada também uma maior concentração de estudos sobre resíduos sólidos, envolvendo aterros, lixiviado e as temáticas sobre mudanças climáticas. A temática foi acompanhada por estudos envolvendo agentes impactantes no clima, políticas públicas, questões socioambientais e econômicas e metodologias para análise dos efeitos das mudanças no clima.

A partir da análise dos termos mais frequentes nas edições da Revista ESA, foi possível identificar 15 temáticas recorrentes, classificadas pela ênfase das publicações nos períodos analisados, como apresenta o Quadro 3.

Apesar das temáticas estarem presentes em praticamente todas as edições, verifica-se que a ênfase e o desdobramento ao longo dos anos foram diferentes, conforme ilustrado nas nuvens de termos.

\section{Financiamento público no âmbito das temáticas da revista}

Nas seções anteriores foram apresentadas as análises decorrentes da identificação das temáticas em engenharia sanitária e ambiental presentes nos resumos da Revista ESA entre 2004 e 2011. Como ilustrado na Figura 1, um dos objetivos da abordagem proposta é combinar resultados da engenharia do conhecimento com outras análises da informetria.

No Brasil, uma dessas combinações possíveis se dá pela análise da presença das temáticas encontradas na revista em projetos financiados pelas organizações públicas de CT\&I. No plano federal, uma das fontes de informação que permite essa verificação é a base de fundos setoriais do MCTI. Os Fundos Setoriais de Ciência e Tecnologia foram criados em 1999 para estabelecer um novo modelo de financiamento de projetos de pesquisa e para apoio ao desenvolvimento e inovação no país (DO VALLE et al., 2002). O objetivo é garantir a estabilidade de recursos para o desenvolvimento de áreas prioritárias para o Brasil, articulado por um novo modelo de gestão, com a participação de vários segmentos sociais, promovendo sinergia entre as universidades, centros de pesquisa e o setor produtivo (FINEP, 2013).

Ao se verificar a presença das temáticas da Revista ESA na base de projetos financiados, pode-se verificar a aderência das temáticas da revista com as prioridades de investimentos em CT\&I do governo brasileiro. Para tal, foi necessário efetivar as seguintes atividades:

1. agrupar os termos presentes no glossário nas temáticas para nortear a inspeção dos projetos financiados (essa escolha deve balancear as presenças do termo na base de projetos, entre as temáticas e entre as palavras-chave dos artigos; no caso da Revista ESA foi estruturado por especialistas um glossário com classificações de 979 termos);

2. identificar os projetos financiados pelos fundos setoriais contextualizados nas temáticas escolhidas (a partir das descrições dos projetos);

3. apurar o montante aplicado nesses projetos; e

4. estabelecer a cronologia de financiamentos para cada temática analisada.

A pesquisa sobre os projetos financiados foi viabilizada pela ferramenta Painel de Conhecimento da Plataforma Aquarius - iniciativa

Quadro 3 - Temáticas recorrentes nas edições da Revista Engenharia Sanitária e Ambiental e respectivas classificações de especialistas.

\begin{tabular}{|l|c|c|}
\hline Ordem & Temática & Categoria atribuída por especialistas \\
\hline 1 & Tratamento de esgoto sanitário & Sistema de esgotamento sanitário \\
\hline 3 & Qualidade ambiental & Qualidade ambiental \\
\hline 4 & Resíduos sólidos & Resíduos sólidos \\
\hline 5 & Metodologia & Metodologia \\
\hline 6 & Estação de tratamento & Sistema de esgotamento sanitário \\
\hline 7 & Saneamento & Política e gestão em saneamento \\
\hline 8 & Saúde pública & Saúde pública \\
\hline 9 & Política ambiental & Política e gestão ambiental \\
\hline 10 & Sistema de abastecimento de água & Tratamento de água \\
\hline 11 & Tratamento de água & Política e gestão em saneamento \\
\hline 12 & Política em saneamento & Recursos hídricos \\
\hline 13 & Coleta de água & Tratamento de efluentes industriais \\
\hline 14 & Efluente industrial & Poluição atmosférica \\
\hline 15 & Poluição atmosférica & Sistema de esgotamento sanitário \\
\hline
\end{tabular}


do MCTI de apoio à governança pública de CT\&I (PACHECO et al., 2012b). O Painel sobre os Fundos Setoriais da Plataforma Aquarius viabiliza o livre acesso a diversas informações sobre os projetos financiados, incluindo os seus objetivos e o valor aportado.

Ao final dessas quatro atividades foi possível identificar a evolução do valor destinado à contratação de projetos associados às 15 temáticas enfatizadas nas edições da revista, conforme ilustra a Figura 9 e a Tabela 9.
Conforme se pode verificar no gráfico da Figura 9, em todas as temáticas pesquisadas há um crescimento significativo no volume de recursos aportados em contratação de projetos de pesquisa e desenvolvimento (P\&D) pelos fundos setoriais entre os períodos 2003-2005 e 2010-2012.

Em alguns casos, esse crescimento no período é coincidente com o aumento do número de artigos publicados nas temáticas financiadas, identificando um alinhamento entre a ênfase dos artigos publicados

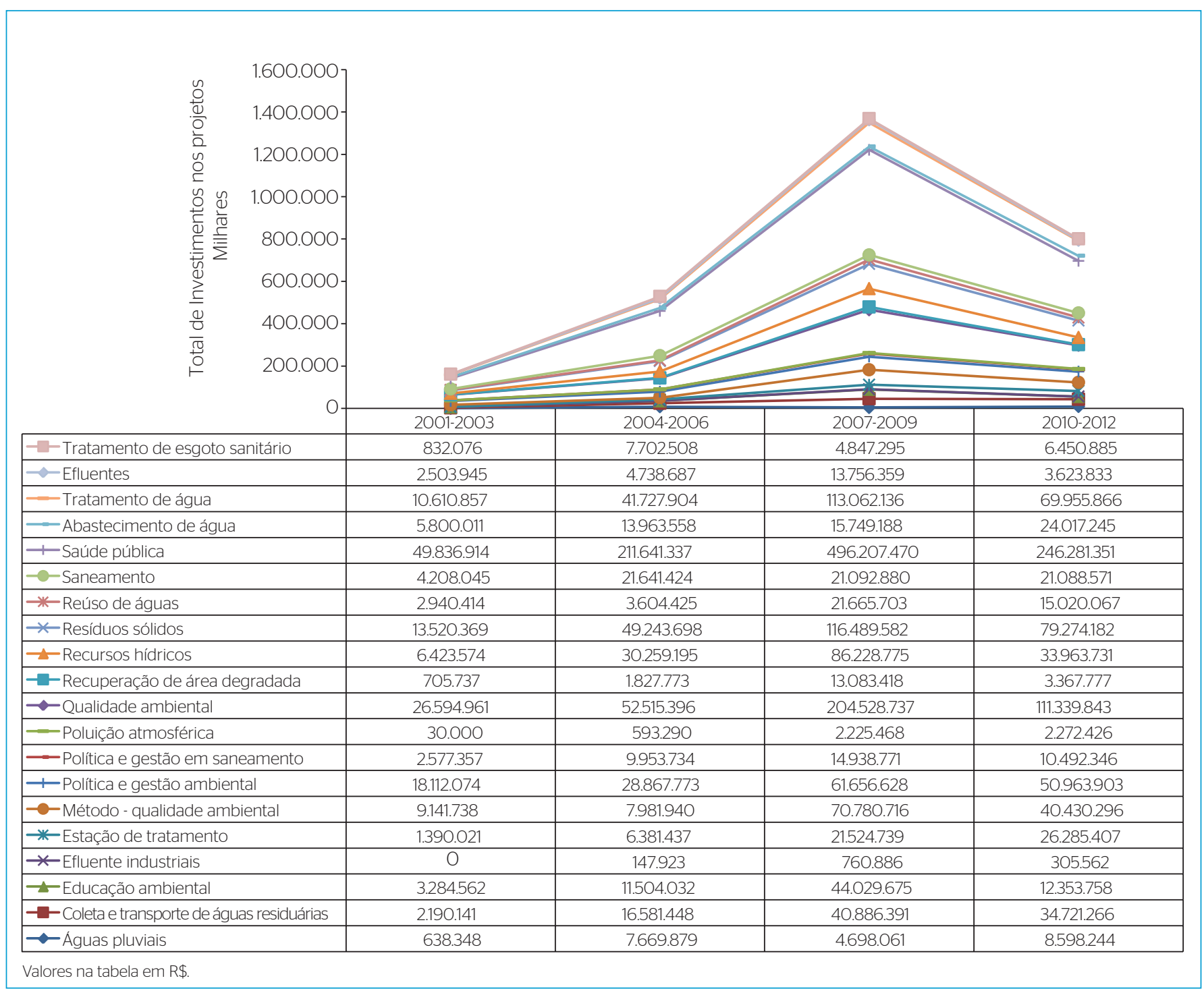

Figura 9 - Evolução dos investimentos pelos fundos setoriais nas temáticas da revista.

Tabela 9 - Evolução dos investimentos nas temáticas sobre o total aplicado pelos fundos setoriais.

\begin{tabular}{l|c|c|c|c} 
& $2001-2003$ & $2004-2006$ & $2007-2009$ & $2010-2012$ \\
\hline Total investido nas temáticas (R\$) & 161.341 .146 & 528.547 .360 & 1.368 .212 .877 & 800.806 .559 \\
\hline Total geral nos fundos (R\$) & 954.715 .222 & 2.548 .410 .521 & 5.463 .873 .746 & 2.269 .119 .805 \\
\hline Porcentagem de temáticas sobre total geral & $17 \%$ & $21 \%$ & $25 \%$ & $35 \%$ \\
\hline
\end{tabular}


na revista e o volume dos investimentos aplicados pelos fundos setoriais. Esse é o caso, por exemplo, da temática "resíduos sólidos", que tanto nos fundos setoriais como na Revista ESA tinha baixa incidência nos primeiros períodos, mas entre 2010 e 2012 foi verificado aumento substancial no aporte de recursos para pesquisa, quando comparado aos primeiros períodos da análise (Tabela 9).

Em outros casos parece haver uma constância na presença editorial das temáticas na revista e uma variação no fluxo de investimentos em P\&D. Esse é o caso, por exemplo, da temática "saneamento" e da temática "águas pluviais", que apresentam relativa constância na ênfase editorial da Revista ESA e uma variação de volume de investimentos (com máximo no período entre 2004-2006 para "saneamento" e entre 2010-2012 para "águas pluviais").

Além do fluxo de recursos aplicados em projetos nas temáticas associadas à Revista ESA, é interessante analisar o volume desses investimentos no cômputo geral dos projetos nos fundos setoriais. Essa comparação está apresentada na Tabela 9. Pode-se notar que houve uma redução no montante total de aplicações nos fundos setoriais, incluindo o total de investimentos em projetos aderentes às temáticas da revista. No entanto, em termos relativos, houve um aumento constante no percentual de participação das temáticas da Revista ESA nos financiamentos dos fundos, que começou com cerca de $17 \%$ do total de investimentos, no período 2001-2003 e, no período mais recente, entre 2010 e 2012, alcançou 35\% do total de investimentos.

Conforme apresentado na Tabela 9, houve uma redução de investimentos na maioria das temáticas analisadas no período 2010-2012, mas observou-se que a diminuição dos investimentos nesse período ocorreu em todas as áreas de pesquisa. No entanto, verifica-se que as temáticas pesquisadas possuem acentuada representatividade nos projetos financiados e que, apesar do corte de investimentos no último período, o percentual relativo de investimentos em projetos contratados nas temáticas ligadas à engenharia sanitária e ambiental dobrou no período.

\section{CONCLUSÕES}

Neste artigo foi analisado o papel da Revista ESA no sistema brasileiro de CT\&I, enquanto agente de memória e difusão de conhecimento em suas temáticas de interesse. Para tal, foi aplicado um modelo multidisciplinar, que combina as abordagens da informetria com técnicas da engenharia do conhecimento, tendo como fontes de informação os artigos publicados entre 2004 e 2012, os Currículos Lattes dos 816 autores desses artigos e, ainda, a distribuição de financiamentos nas temáticas da revista presentes nos fundos setoriais do MCTI.

No plano da informetria, verifica-se que os autores utilizaram uma ampla gama de termos para indexarem seus artigos publicados na Revista ESA, que, segundo especialistas no domínio da revista, representam 14 categorias de temas afetos à engenharia sanitária e ambiental. Quando comparadas com a totalidade de currículos do sistema brasileiro de CT\&I, verifica-se que a Revista ESA tem significativa abrangência de autores para os temas de "tratamento de água" e "política e gestão em saneamento". Além disso, verificou-se que os autores da revista têm, em sua ampla maioria, doutorado e vínculo com o setor acadêmico (ainda que se registre a presença de consultores e profissionais atuantes em outros setores).

Em relação aos financiamentos públicos em domínios relacionados às temáticas de publicação da revista, evidencia-se um aumento significativo na participação percentual dos investimentos federais em CT\&I, mesmo quando os investimentos totais caíram. Entre 2001 e 2011, o investimento dos fundos setoriais nas temáticas de publicação da Revista ESA subiu de 17 para 35\% do total, indicando que suas temáticas têm crescido de interesse e priorização nos investimentos governamentais.

Percebe-se, portanto, que a análise conjunta da evolução da produção de conhecimentos e de fomento público nas áreas de publicação da revista serve de insumo à tomada de decisão de diferentes atores no sistema de CT\&I. Para os editores da Revista ESA, podem identificar o papel estratégico que desejam para a revista no sistema brasileiro de CT\&I. No caso de pesquisadores das áreas de publicação da revista, os estudos ajudam a verificar o perfil e a cronologia do conhecimento produzido no país em suas áreas de atuação, informação de interesse potencial também para gestores em CT\&I, interessados em fomentar esse conhecimento. Finalmente, as análises podem interessar, também, a organizações empresariais afetas pelas oportunidades de inovação nas áreas de publicação da revista.

\section{AGRADECIMENTOS}

Os autores agradecem a Juliana T. Sartortt e a Maria Elisa Rosa pelo trabalho de extração e tratamento dos dados bibliométricos desta pesquisa.

\section{REFERÊNCIAS}

ALMIND, T.C. \& INGWERSEN, P. (1997) Informetric analyses on the world wide web: methodological approaches to 'webometrics'. Journal of Documentation, v. 53, n. 4, p. 404-426.
BJÖRNEBORN, L. \& INGWERSEN, P. (2004) Toward a basic framework for webometrics. Journal of the American Society for Information Science and Technology, v. 55, n. 14, p. 1216-1227. 
BROOKES, B.C. (1988) Comments on the scope of bibliometrics. In: EGGHE, L.; ROUSSEAU, R. (Eds.) Informetrics 87/88: select Proceedings of the first international conference on bibliometrics and theoretical aspects of information.

CAPES - COORDENAÇÃO DE APERFEIÇOAMENTO DE PESSOAL DE NIVEL SUPERIOR. (2O11) Plano Nacional de Pós-Graduação. v. I. Brasília: CAPES.

CECl, F.; PIETROBON, R.; GONÇALVES, A.L. (2012) Turning text into research networks: information retrieval and computational ontologies in the creation of scientific databases. PLoS One, v. 7 , n. 1, p. e27499.

CECI, F.; SILVA, D.C.; SELL, D.; GONÇALVES, A.L. (2010) Towards a semi-automatic approach for ontology maintenance. In: Contecsi International Conference on Information Systems and Technology Management, 7. São Paulo.

DO VALLE, M.G.; BONACELLI, M.B.M.; SALLES FILHO, S.L.M. (2002) Os fundos setoriais e a política nacional de ciência, tecnologia e inovação. In: Anais do XXII Simpósio de Gestão da Inovação Tecnológica. Salvador.

DOBROV, G.M. \& KARENNOI, A.A. (1969) The informational basis of scientometrics. In: MIKHAILOV, A.I., et al. (Eds.) On theoretical problems of informatics. Moscou: VINITI/FID. p. 165-191.

FINEP. O que são os Fundos Setoriais. Disponível em: http://www.finep. gov.br/fundos_setoriais/fundos_setoriais_ini.asp?codSessaoFundos=1. Acesso em: 10 outubro 2013.

HUANG, M.H.; CHANG, H.W.; CHEN, D.Z. (2012) The trend of concentration in scientific research and technological innovation: a reduction of the predominant role of the U. S. in world research \& technology. Journal of Informetrics, v. 6, n. 4, p. 457-468.

NACKE, O. (1979) Informetrie: ein neuer Name für eine neue Disziplin. Nachrichten für Dokumentation, v. 30, n. 6, p. 219-226.

OTLET, P. (1934) Traité de documentation: le livre sur le livre, théorie et pratique. Editiones Mundaneum, [Treatise on documentation. The book on the book. Theory and practice], Brussels: Van Keerberghen.

PACHECO, R.C.S.; SELL, D.; STEIL, A.V.; CECI, F. (2012a) A Revista Brasileira de Ciências Ambientais no contexto do Sistema Brasileiro de CT\&l. Revista Brasileira de Ciências Ambientais (Online), v. 12, n. 26, p. 75-100.

PACHECO, R.C.S.; SELL, D.; TODESCO, J.L. (2012b) Plataforma de Gestão Estratégica à Governança Pública em CT\&l. In: 70 Congresso Associação Brasileira das Instituições de Pesquisa Tecnológica e Inovação ABIPTI. Local: Hotal São Marco. Brasilia, DF.

PRITCHARD, A. (1969) Statistical Bibliography: an interim bibliography. London: North-Western Polytechnic, School of Librarianship. 60 p.

SAMPAIO, M.I.C.; SABADINI, A.A.Z.P.; LINGUANOTTO, A.R.J. (2002) Periódicos científicos: características e exigências. Mudanças Psicologia da Saúde, v. 10, n. 1, p. 129-277.

WILSON, C.S. (1999) Informetrics. Annual Review of Information Science and Technology (ARIST), v. 34, p. 107-247.

WITTER, G.P. \& MARIA, F.A. (2005) Velhice no banco de teses da Capes (2000 e 2001). In: WIT TER, G.P. (Org.). Metaciência e psicologia. Campinas: Alínea. 